\title{
Assalariamento na Terra Indígena Mangueirinha: estratégias Guarani e Kaingang
}

\author{
Wages in the Mangueirinha Indigenous Land: Guarani and Kaingang strategies
}

Asalariados en la Terra Indígena Mangueirinha: estrategias Guarani y Kaingang

\author{
Antonio Cavalcante Almeida ${ }^{1}$ \\ Aline Cavalheiro ${ }^{2}$ \\ Miguel Ângelo Perondi ${ }^{2}$
}

Recebido em: 19/11/2019. Revisado e aprovado em: 26/02/2020. Aceito em: 21/03/2020 DOI: http://dx.doi.org/10.20435/inter.v21i3.2828

\begin{abstract}
Resumo: Os povos indígenas do Brasil vêm passando por transformações desde o período de colonização, quando o contato com os europeus iniciou seu processo de hibridação cultural. Atualmente, o meio de vida tradicional indígena busca estratégias de assimilação cultural, ao mesmo tempo que procura resistir e conservar sua identidade junto à sociedade envolvente. Nesse novo formato, os povos indígenas necessitam cada vez mais do uso do dinheiro, e, tendo em vista as poucas opções de renda monetária dentro da Terra Indígena ( $\mathrm{TI}$ ), o recurso mais comum tem sido buscar complementar a renda fora do seu território. Assim, o presente estudo teve por objetivo analisar as estratégias e consequências do processo de assalariamento dos povos Kaingang e Guarani da TI Mangueirinha, PR. Para tanto, a pesquisa buscou entrevistar agenciadores, lideranças e trabalhadores indígenas que estão inseridos no processo de assalariamento indígena. Ao final, percebeu-se que as lideranças indígenas têm um papel significativo no processo de assalariamento formal dos indígenas, assim como identificaram-se respostas distintas desse processo, de acordo com a cultura envolvida.
\end{abstract}

Palavras-chave: assalariamento indígena; povos indígenas; Guarani; Kaingang.

Abstract: Indigenous peoples in Brazil are undergoing transformations since the colonization period, when the contact with the European caused a cultural hybridization process. Currently, the traditional indigenous livelihood seeks strategies for cultural assimilation while trying to resist and preserve its identity with the surrounding society. In this new economic format, in which indigenous peoples increasingly need the use of money, and, given the few options for obtaining income within the Indigenous Land (TI), the most common use has been to seek additional income outside its territory. Thus, this study aimed to analyze the strategies and consequences of the wage process of Kaingang and Guarani people in IT Mangueirinha, PR. Therefore, the research sought to interview bookies, indigenous leaders, and workers who fall within the indigenous wage process. In the end, we realized that these Indigenous leaders have a significant role in the formal salaried employment process of the Indigenous, as well as we identified different responses of the process, according to the culture involved.

Keywords: indigenous wage; indigenous people; Guarani; Kaingang.

Resumen: Los pueblos indígenas de Brasil han experimentado transformaciones desde el período de colonización, cuando el contacto con los europeos comenzó su proceso de hibridación cultural. Actualmente, el sustento indígena tradicional busca estrategias para la asimilación cultural, mientras trata de resistir y preservar su identidad con la sociedad circundante. En este nuevo formato económico, los pueblos indígenas necesitan de cada vez más dinero y, teniendo en cuenta las pocas opciones de ingresos dentro de la Tierra Indígena ( $\mathrm{TI}$ ), el recurso más común ha sido buscar complementar los ingresos fuera de su territorio. Por lo tanto, el presente estudio tuvo como objetivo analizar las estrategias y las consecuencias del proceso asalariado de los pueblos Kaingang y Guaraní de TI Mangueirinha, PR. Con este fin, la investigación buscó entrevistar a agentes, líderes y trabajadores indígenas que se insertan en el proceso de salario indígena. Al final, se notó que los líderes indígenas tienen un papel importante en el proceso de salario formal de los indígenas, así como se identificaron respuestas distintas de este proceso, de acuerdo con la cultura involucrada.

Palabras clave: asalariados indígenas; pueblos indígenas; Guaraní; Kaingang.

\footnotetext{
$\overline{1}$ Instituto Federal de Educação, Ciência e Tecnologia do Ceará (IFCE), Campus Fortaleza, Ceará, Brasil.

2 Universidade Tecnológica Federal do Paraná (UTFPR), Pato Branco, Paraná, Brasil.
} 


\section{INTRODUÇÃO}

Desde o "descobrimento" da América, os povos autóctones sofrem a imposição cultural eurocêntrica dos colonizadores, a qual transformou suas vidas. Essa mudança já custou milhares de vidas e a extinção de muitas etnias. Contudo também ocorreram estratégias de adaptação e resistência que permitem ainda hoje contabilizar no território brasileiro mais de 200 etnias e 800 mil pessoas declaradamente indígenas (ISA, 2015).

O maior impacto da modernidade sobre a organização econômica dos povos originários foi transferir sua motivação econômica da subsistência do grupo para o indivíduo, num processo de mercantilização que passou a tornar necessária a aquisição de bens e trouxe sentido e utilidade ao dinheiro, um fenômeno social que transformou de forma irreversível a realidade dos povos indígenas e os relacionou aos mercados, por mais precários que sejam.

Atualmente, muitas Terras Indígenas (TI) não têm condições de suprir a subsistência da comunidade de maneira sustentável, pois não dispõem de terra suficiente para manter um sistema de produção distinto do tradicional de seus antepassados. Os recursos naturais estão se tornando híbridos com o advento do uso de tecnologias intensivas de capital e insumos, o que permite a concentração do uso da terra por representantes do coletivo. Dessa forma, uma grande parte dos indígenas "desempregados do coletivo" acaba por buscar recursos externos via políticas públicas e mercantilização de sua força de trabalho no entorno. Esse contato permanente com a sociedade envolvente ressignificou de forma distinta e própria cada uma das culturas dos povos indígenas, transformando seus hábitos cotidianos (MOURA; BATISTA; MOREIRA, 2010; LAZZAROTTO, 2007).

Sabe-se que à medida que o contato com o não indígena se tornou frequente, para muitos povos indígenas, a hibridez cultural aconteceu de forma gradual. Assim, os hábitos ocidentais foram permeando a tradição indígena até fazer parte do seu meio de vida e torná-la refém do uso de recursos monetários. Quando se está inserido em uma sociedade regida pela lógica de mercado, torna-se hipoteticamente impossível sobreviver sem fazer parte dela, principalmente se os meios disponíveis não propiciam a independência econômica, que é o caso de muitos povos indígenas do sul do Brasil. Logo, a inserção nos mercados de trabalho se tornou um meio de sobrevivência, o que não significa, necessariamente, que fazer parte de uma lógica social e econômica de mercado implique perda inexorável da identidade cultural indígena.

Essas transformações revelam a hibridação sugerida por Canclini (2008), sendo raros os casos de economias indígenas que sejam absolutamente autossuficientes, visto que produzir o suficiente para o consumo acaba se tornando insuficiente para manter uma sociedade que aos poucos vai valorizando o valor de troca em detrimento do valor de uso, uma questão-chave que determina e delimita a origem da mercadoria no seu aspecto conceitual.

Portanto o objetivo deste trabalho é analisar as estratégias e as consequências do processo de assalariamento das populações indígenas Guarani e Kaingang que coabitam a Terra Indígena Mangueirinha, no Estado do Paraná (PR), a partir de suas diferentes culturas submetidas a um mesmo processo e contexto de mercantilização.

Neste objetivo, observa-se que o sentido de estratégia aqui utilizado é o mesmo empregado por Bourdieu (2004), que, em síntese, refere-se à necessidade constante de manter ou buscar formas eficientes de adaptabilidade às novas circunstâncias. Para o autor, as estratégias são produtos do senso prático, imbuídas em regras de um determinado "jogo social", o qual se é 
aprendido desde a infância de cada indivíduo. Assim, sempre que surgem modificações nas circunstâncias, é necessário utilizar novas práticas estratégicas de se adaptar as mudanças. Nesse sentido, buscou-se visualizar o assalariamento na TI Mangueirinha como uma nova prática estratégica que surgiu pela necessidade imposta por novas circunstâncias econômicas e sociais, mas que é realizada de acordo com suas regras culturais.

A Terra Indígena Mangueirinha está localizada na região Sudoeste do Paraná nas divisas dos municípios de Mangueirinha, Coronel Vivida e Chopinzinho. Atualmente, sua população indígena é de 1.457 pessoas numa área de 16.376 hectares, sendo que 8.804 ainda estão sub judice. A TI é dividida em seis comunidades: Passo Liso, Mato Branco, Paiol Queimado, Água Santa, Palmeirinha do Iguaçu e Aldeia Sede, onde estão edificados a escola, o posto de saúde e o posto da Funai (ALMEIDA, 2013).

A TI Mangueirinha é de posse dos índios Kaingang, contudo, nela também habitam índios Guarani Mbyá, em uma rara união de dois povos historicamente rivais, que vem ocorrendo já há muitas décadas. Os Guarani habitam a Comunidade Palmeirinha do Iguaçu e desenvolvem as suas tradições culturais e atividades econômicas nessa localidade doada pelo povo Kaingang.

A população de estudo foi limitada geograficamente pelas comunidades Aldeia Sede e Paiol Queimado (Kaingang) e Palmeirinha do Iguaçu (Guarani), as quais concentram o maior número de indígenas que vendem sua força de trabalho. Foram realizadas entrevistas semiestruturadas com alguns dos indígenas assalariados, seus agenciadores e suas lideranças indígenas. Foram instrumentos da coleta de dados: o gravador, o caderno de campo e a máquina fotográfica, para estabelecer o registro sistemático da observação participante.

Esta pesquisa demandou aproximadamente quinze visitas à TI Mangueirinha, entre dezembro de 2013 e outubro de 2015. Dessa forma, para a coleta de dados foi utilizado um questionário semiestruturado, com gravação de áudio e, posteriormente, transcrição das entrevistas. O número de indígenas assalariados entrevistados foi limitado pela dificuldade de coincidir agenda livre de seus horários de trabalho. Mesmo assim, teve-se êxito em obter sete entrevistas com indígenas assalariados, sendo dois Guarani e cinco do grupo Kaingang. Além desses, corroboraram com a pesquisa os caciques Guarani e Kaingang, outros três indígenas Guarani, dois Kaingang e uma funcionária de uma das empresas agenciadoras da mão de obra indígena, totalizando quinze entrevistas, além das observações anotadas no diário de campo.

A análise dos dados se baseou na organização das laudas transcritas das gravações e do diário de campo, comparando-as com a bibliografia estudada. E, assim, como advertiu Minayo (1994), procurou-se responder às questões inicialmente formuladas como objetivo de enriquecer ainda mais esse universo de pesquisa.

\section{OS POVOS GUARANI E KAINGANG}

Os Guarani pertencem ao tronco linguístico Tupi, da família linguística Tupi-Guarani, e são subdivididos em três subgrupos, os Kayová, os Ñandéva e os Mbýa. Os três subgrupos derivam de um mesmo núcleo, contudo cada um tem suas particularidades cosmológicas e culturais (ROSA, 1999).

A principal referência que se faz à cosmologia dos Guarani é a sua busca pela "Terra sem mal" (YvyMarãey), uma terra paradisíaca, onde os homens estariam seguros de doenças, restrições sociais e da morte. A crença dos Guarani em uma terra sem mal foi muito usada pelos 
estudiosos para justificar a migração constante desse povo. No entanto existe outro significado, pouco relevado na literatura, para a YvyMarãey, de algo não místico, mas físico: uma terra boa, produtiva, um espaço físico e social, onde seria possível expandir a existência Guarani (ROSA, 1999; CLASTRES, 2003).

Na economia Guarani, as atividades extrativistas de frutos silvestres são mais utilizadas para diversificar a alimentação, enquanto as artesanais auxiliam a renda da família na troca ou compra de produtos que eles não têm. O artesanato envolve toda a família na produção de utilitários (balaios, cestos, peneiras, chapéus) e de "enfeites" (colares, brincos, arco e flecha, espadas), a matéria-prima para a confecção é a taquara, penas de aves (que encontram caídas, pois eles não tiram), sementes e caroços de frutos locais (PIRES, 1975).

Os Kaingang fazem parte da família Jê, do tronco linguístico Macro-Jê, assim como outras etnias indígenas, como os Bororos e os Krenák, entre outros. O termo Kaingang pode ser encontrado em diferentes formas de escrita, uma vez que o contato com o não índio e com instituições sociais não indígenas ao longo da história propiciou muitas variações na grafia: Caingang, Kaingangue, Kaingáng e Kaingang (ALMEIDA, 2013).

A presença das populações indígenas no território paranaense, conforme estudos arqueológicos e antropológicos, é de cerca de 3 mil anos. Muitas análises apontam para a hipótese de deslocamento de habitantes de outras áreas no sentido da região Sul do Brasil por algum motivo ainda desconhecido, embora um estudo de relevo geográfico mostre que se dirigiram a uma região de planalto semelhante ao seu habitat originário. Assim, o certo é que as pesquisas arqueológicas indicam que os Jê Meridionais (Kaingang e Xokleng) deslocaram-se do Brasil Central (nascentes do Rio São Francisco e Araguaia) em direção à região Centro-Sul, estabelecendo-se nas regiões hoje conhecidas como estados do Paraná, Santa Catarina, Rio Grande do Sul e São Paulo, além da província de Missiones, na Argentina, aproximadamente por volta de 3 mil anos (ALMEIDA, 2013 apud MOTA, 1994; NOELLI, 2000; TOMMASINO, 2000).

Entre os Kaingang, a organização política reflete seus traços culturais, num sistema organizado em metades exogâmicas, "isto é, pela complementaridade entre os indivíduos que trazem a marca cultural conferida de Kamẽ e Kaũru" (ALMEIDA, 2013, p. 93). Esse dualismo é parte intrínseca da cosmologia Kaingang, baseado no universo dos mitos; as metades ao mesmo tempo se opõem e se unem, diferenciam-se por pinturas e nutrem uma relação sociocultural coesiva, por terem características distintas: os Kamẽ são perseverantes, são os que estão sempre à frente; os Kaĩru têm iniciativa, mas não são persistentes.

Desse modo, a divisão social em duas partes que se opõem e se complementam, presente nos grupos pertencentes ao tronco Macro-Jê, foi a base de todos os ritos socioculturais que caracterizam os Kaingang, entre esses, o casamento, que só pode ser realizado com a bênção dos ancestrais quando une as duas metades, ou seja, um Kaĩru só pode casar-se com uma Kamẽ e vice-versa. Assim, conforme Almeida (2013), mesmo diante das transformações ocorridas na Terra Indígena Mangueirinha, ainda é possível observar esses elementos de complementaridade e coesão social no universo das aldeias na referida terra indígena.

O principal meio econômico dos Kaingang é a agricultura, no entanto Pires (1975) ressalta que, já em meados dos anos 1970, em épocas de penúria, os Kaingang da Terra Indígena Mangueirinha prestavam serviços aos não índios para sustentar a família, porém, entre eles, trabalhar para o "branco" era vergonhoso, e os que não precisavam se prestar a isso eram mais bem vistos no grupo. 


\section{A MERCANTILIZAÇÃO DA FORÇA DE TRABALHO}

Long (1986) explica a mercantilização como a instalação de uma crescente necessidade de produzir mercadorias para poder saciar a própria necessidade de consumir mercadorias, conduzindo a um crescente processo de individualização e monetarização das relações sociais.

À medida que o mercado foi se instituindo, a divisão social do trabalho e o trabalho assalariado se tornaram um dos principais meios de acumulação de riquezas. As relações de mercado passaram a centrar a maioria das sociedades, em que, de um lado, há grandes mercadores buscando expandir seu capital financeiro, utilizando para isso a mão de obra de terceiros em troca de uma pequena fração de seu lucro: o salário. E, em outro, há pessoas que vendem sua força de trabalho, para as mais diversas funções produtivas, como meio de obter condições financeiras para a troca mercantil (SOUZA, 1980; WOLECK, 2002).

Para Polanyi (2000), existe um novo sentido para as relações sociais no capitalismo, um sentido que inverteu a ordem natural das coisas até então, ou seja, em vez de as relações sociais definirem as relações econômicas, como ocorre na maioria das culturas que se conhece, as relações econômicas passaram a definir as relações sociais. A mercantilização, portanto, eliminou os antigos padrões de relacionamento social e os recolocou baseados num sistema de mercado, criador de preços. Relações de reciprocidade e redistribuição para a comunidade foram então deslocadas progressivamente para uma relação mercantil de troca instantânea.

A expansão dos núcleos capitalistas vem atingindo todas as atividades tradicionais e nesse choque as destrói ou as modifica, recriando novos espaços econômicos onde reinava uma economia tradicional. Segundo Souza (1980), como meio de sobrevivência, as pessoas são impulsionadas a mudar o seu meio de vida num processo que muitas vezes envolve o assalariamento, seja temporário, seja permanente.

Chayanov (1981), no contexto dos camponeses da Rússia do início do século XX, considerava que a estratégia de buscar o trabalho assalariado é própria dos povos tradicionais, o que não significava que eles estavam se capitalizando, mas buscando entesouramento para melhorar a sua condição de vida tradicional. O autor explica que é o equilíbrio entre a satisfação da demanda familiar e a penosidade do trabalho que determina o grau de "autoexploração" entre os povos tradicionais; nesse caso, a tendência é diminuir a intensidade do trabalho sempre que as necessidades familiares estiverem satisfeitas e aumentar em casos de infortúnios da terra ou de poucos membros da família aptos ao trabalho.

Schneider (2003) chamou atenção para a combinação de atividades agrícolas e não agrícolas com o tema da pluriatividade, uma estratégia de ocupação da força de trabalho que se intensificou com o advento da mecanização agrícola e que, ao diminuir a demanda de trabalho, permitiu, por outro lado, que membros da família se integrassem ao mercado de trabalho não agrícola. Essa forma de diversificar a renda da família rural já era evidenciada por Graziano da Silva (1997) no debate acerca do novo rural brasileiro, entretanto o que se distingue neste estudo é abordar o papel (ou poder) das rendas não agrícolas em transformar as estratégias de meios de vida. Portanto, como em Ellis (2000) e Perondi (2007), considera-se aqui que a possibilidade de dispor de uma renda não agrícola no portfólio de possíveis ocupações de uma família numa comunidade tradicional (ou ancestral como a dos indígenas) transforma suas vidas para uma forma muito diferente da usual daqueles que não podem dispor de uma.

Observa-se, assim, que a Era Moderna possibilitou a pessoas despossuídas serem assalariadas a partir da divisão social do trabalho e permitiu que esses indivíduos obtivessem 
bens e serviços de que necessitam ou desejam (WOLECK, 2002). Mas também imagine se os indivíduos não forem despossuídos de uma comunidade (ou aldeia); nesse contexto, a renda não agrícola traz novas possibilidades de poder entre os que não dispunham de uma.

É importante ressaltar que os indígenas seguem uma lógica de vida muito distinta do ocidental, sendo regidos pela subsistência. Por mais próximos que estejam dos centros urbanos, e mesmo que estejam inseridos no processo mercantil, isso não significa que estejam abandonando o seu modo tradicional, mas transformando-o. A hibridação de seus hábitos e seus costumes faz parte de sua lógica, pois é uma estratégia de subsistir à modernidade capitalista.

\section{O PROCESSO DE ASSALARIAMENTO DOS INDÍGENAS}

Na TI Mangueirinha, as lideranças foram chaves para a primeira inserção dos indígenas no mercado de trabalho das indústrias. A pouca opção de trabalho dentro das aldeias, a carência de diversidade natural para as atividades tradicionais e a necessidade cada vez maior do uso do dinheiro para a subsistência fez com que os indígenas se interessassem pelos empregos oferecidos nos centros urbanos e, com pouca informação sobre o funcionamento do mercado de trabalho, passaram a demandar que o cacique mediasse a contratação.

Eles começaram foi no ano retrasado, na verdade, como eu já era liderança na época, né, eles procuravam assim, por exemplo, diziam assim se nós como liderança poderíamos ajudar eles assim achar emprego, então daí a gente procurou essas empresas. (Cacique Guarani).

No ano de 2012, após o diálogo dos Caciques Guarani e Kaingang com os responsáveis por uma empresa de eletrodomésticos, foi realizada uma reunião na Aldeia Sede da TI Mangueirinha e outra na Aldeia Palmeirinha do Iguaçu com os funcionários dos Recursos Humanos (RH) dessa empresa. Depois, os indígenas interessados foram convidados a realizar entrevistas na empresa.

Eles vieram aqui para fazer uma reunião, daí o cacique avisou, né, para quem queria ir. Daí eu fui lá, eles preencheram uma ficha, daí depois nos levaram para entrevista lá, daí eu achei bom. Fiz a experiência, 3 meses, daí deu, daí eu fiquei. (Indígena assalariada K4).

Eles vieram aqui, daí fizeram uma reunião com quem queria trabalhar, daí nós demos o nome, preenchemos o currículo ali mesmo, dai eles chamaram nós pra experiência, daí foi assim. (Indígena assalariado K5).

Depois que a primeira empresa passou a contratar a mão de obra dos indígenas, outras também procuraram as lideranças para oferecer emprego assalariado. A procura dos indígenas por emprego veio em boa hora, argumenta uma funcionária de uma das empresas contratantes da força de trabalho indígena:

Nós fomos até lá, conhecemos a cultura deles, explicamos direitinho como funcionava a empresa. O principal motivo da busca de mão de obra em áreas indígenas é a dificuldade na contratação de profissionais. (Agenciador).

Do ponto de vista das lideranças indígenas, o trabalho assalariado foi uma boa estratégia para reduzir o alcoolismo nas aldeias.

Depois que começou os índios trabalhar fora melhorou bastante, eu até acreditava que nós ia ter muito problema por isso, porque antes de eles terem esses empregos se via muito índio bêbado nas estradas e acidente com eles, e daí quando começou essas firma a gente pensou, bom agora sim que vão beber... E não, a gente se enganou até, tem o índio que bebe mesmo, 
mas muito pouco, então até uns que bebiam muita cachaça hoje não bebe. A gente pensou que ia aumentar o índice de bebida alcoólica, mas diminuiu. Eu acho que eles começaram a ter mais condições de comprar as coisas, porque às vezes eles lutavam aí com a erva e o artesanato e conseguiam de 40 a 50 real na semana, não dava pra fazer o rancho que eles precisavam, então eles compravam alguma coisinha e mais cachaça, né. Eagora não, agora eles fazem o rancho deles. (Cacique Kaingang).

Quando as condições agrícolas não são favoráveis, é própria das populações tradicionais a venda da força de trabalho, trata-se de uma tentativa de buscar liquidez para manter o seu modo de vida, adicionando a estratégia do salário à vida tradicional (CHAYANOV, 1981; FRIEDMANN, 1978).

\subsection{0 perfil dos indígenas assalariados}

Entre os Guarani, as entrevistas com indígenas assalariados ocorreram somente com mulheres; uma delas tinha o salário como única fonte de renda de subsistência da família e outra considerava o salário de forma complementar à subsistência. Segundo elas, atualmente todos os assalariados nas empresas manufatureiras da região que se originam no universo de povos Guarani são do sexo feminino, pois todos os homens, que eram a maioria no início, acabaram sendo demitidos ou demitindo-se.

Dos trabalhadores assalariados Kaingang entrevistados, quatro eram homens e uma mulher. Nesse caso, é importante destacar que um dos entrevistados vivia entre os Guarani há mais de 20 anos, falava língua nativa e confeccionava artesanato, sendo que o trabalho assalariado dele era a principal fonte de renda da família. Os outros quatro que vivem em terra Kaingang não falavam a língua nativa nem confeccionavam artesanato, usavam o salário para uso próprio e, quando necessário, para complementar a renda da família.

Entre os assalariados Kaingang, o número de indígenas de homens é maior que o de mulheres e todos numa faixa etária média de 20 anos. Alguns deles tomaram a decisão de trabalhar em grupo, como relata o entrevistado assalariado K5: "Eu fico bastante com os meus amigos porque nós começamos a trabalhar juntos, eles trabalham todos junto comigo, no mesmo horário [...]" (Entrevistado assalariado K5).

Os indígenas Kaingang mais velhos contam como a rotina da comunidade tem se modificado ao longo dos anos. As atividades de coleta e confecção artesanal para a venda, que antigamente ocupava os homens e as mulheres indígenas, hoje já não são tão significativas, como relatam os entrevistados $\mathrm{K} 6$ e K7:

Teve um tempo que nós coletava o pinhão, na época certa que ele caía do pé, e já tinha um comprador certo, todo ano nós vendia tudo pra ele, dava bastante. Um que outro que ia vender na estrada, porque vendia bem também, mas hoje não vende. Já nem tem mais tanto pinhão e ficar na estrada vendendo hoje não dá nada. A gente tem pra vende aqui, pra quem vem e pede, mas é pouca coisa. (Entrevistado K6).

Artesanato tem, mas é mais assim pra expor nas festa, tem as mulheres que fazem pra vender na cidade, mas que nem nós tinha o centro de exposição ali que ficava cheio, não tem mais. (Entrevistado K7).

Mesmo com as mudanças socioculturais, os professores indígenas Kaingang fazem questão de ensinar os hábitos tradicionais para as crianças na escola, realizam atividades práticas para 
reconhecer as ervas e os frutos mais usados na medicina e culinária, ensinam a confecção de artesanatos, pinturas corporais e danças.

Como argumenta a entrevistada $\mathrm{K} 6$, os adultos não esperam que as crianças tenham os mesmos hábitos que os seus antepassados e nem querem isso, essas atividades são formas de manter a ligação deles com as suas origens, para que eles entendam a sua própria história:

A gente tenta trabalhar o máximo com as crianças, porque pra eles é complicado. Convivem muito com o branco e a gente sabe que algumas têm vergonha de ser índio, porque escutam muita coisa errada lá fora, então nossa intenção é trabalhar pra que eles tenham orgulho de ser índio. (Entrevistada K6).

Os indígenas têm consciência das transformações culturais que vêm ocorrendo dentro da TI Mangueirinha e do quão híbrida é hoje, se comparada aos seus antepassados. Contudo os Kaingang argumentam que muitas das mudanças recentes foram para melhor, que sua qualidade de vida melhorou e que as mudanças culturais são vistas como negativas somente pelos não índios, que não compreendem porque os indígenas estão satisfeitos e lutam para melhorar ainda mais:

O branco só procura o índio quando precisa, nunca nenhum branco veio aqui porque queria conhecer e entender nossa cultura, só quando tem que escrever sobre a gente nas universidades. (Entrevistada K6).

O artesanato é bom a gente sempre fazer, não perder, sempre passar pro filho aprender fazer, por que não é um artesanato assim pra ornamento, pra bonito, tem coisas ali que você precisa, é pro dia a dia, uma peneira, um balaio. Então isso ai é bom fazer, mas ter o artesanato como uma fonte de renda, fonte de subsistência, isso já não dá mais, porque ele não tem grande comércio, pra ser fonte de subsistência deveria ter um comércio, e isso não tem. Então a gente não fica preocupado com isso, claro que a gente quer que eles nunca esqueçam, que aprendam fazer a flecha, o balaio, a peneira, o cesto, mas nem todos fazem, porque a cultura vai mudando, e tem coisas que a gente tem que lutar pra não perder, o artesanato é um deles, a língua materna também. (Cacique Kaingang).

Entre os Guarani, a língua nativa permanece como a principal falada dentro da aldeia Palmeirinha do Iguaçu, alguns deles falam o português com dificuldade, demoram um pouco para formar frases, procurando as palavras certas. O sotaque forte de alguns lembra o de um estrangeiro falando português, pois a língua nativa Guarani exige um movimento labial diferente. Algumas crianças aprendem a falar português somente quando vão para a escola na aldeia; em casa, falam só a língua nativa com os familiares.

Mas o idioma não dificulta a comunicação com as crianças Guarani, com gestos e sinais elas davam um jeito de perguntar sobre o gravador, a câmera fotográfica e, também, de pedir colo. Espontaneidade que diminui entre os adolescentes e desaparece entre os adultos, a precaução é uma das principais características dos Guarani da TI Mangueirinha.

O artesanato também é uma prática que persiste na Aldeia Palmeirinha do Iguaçu e continua, nos dias atuais, representando a principal fonte de subsistência para a maioria das famílias Guarani. No dia a dia, os indígenas vendem seus artesanatos no acostamento das rodovias. Geralmente, as mulheres confeccionam e os homens vendem, mas todos sabem confeccionar e se dispõem a vender.

Na fala do cacique Guarani, a seguir, percebe-se o orgulho em preservar a língua nativa e o artesanato e, ao mesmo tempo, a inviabilidade de manter outros hábitos tradicionais. A busca 
pelo caminho entre o moderno e o tradicional incentiva os indígenas a buscar por outras fontes de renda que melhoram suas condições de vida, mas, ao mesmo tempo, alteram a cultura.

A gente procura manter bastante a cultura, a língua. Não é 100\%, nós também temos nossos problemas, mas a gente incentiva muito, principalmente os jovens, as crianças, tentamos trabalhar na escola, todo o desenvolvimento da cultura, né. Assim, comparando com outras culturas também, porque hoje não tem como você sobreviver só da natureza, hoje você precisa de dinheiro, precisa de uma boa vida, hoje a gente tem que ter carro pra se locomover. Eu procuro, por exemplo, na escola, tem muitos eletrônicos, meios de comunicação, então usar isso pra divulgar a língua, a cultura, os meios de sobrevivência, usar a favor da cultura, mostrar pras outras culturas, pra sociedade em geral que não é bem assim... Também nós temos problemas, mas a cultura não tá acabando, principalmente aqui. Então nós trabalhamos dessa forma, sabe, eu gosto de conversar, divulgar, que cheguem na aldeia, vejam a situação, principalmente os da cidade que, assim, às vezes moram no município e nem sabem se existe um indígena. (Cacique Guarani).

A população Guarani é menor que a de Kaingang na TI Mangueirinha, atualmente existem cerca de 30 famílias Guarani e 200 famílias Kaingang. Esta é uma variável que facilitou para o Guarani manter a língua nativa, além do aspecto histórico-cultural que faz com que eles mantenham certo distanciamento do não índio, no que diz respeito ao casamento. Para o cacique Guarani, a proibição do casamento com brancos ajudou na preservação de sua língua, pois, no ponto de vista dele, foi a mistura de Kaingang com branco que facilitou a perda da língua nativa Kaingang na TI Mangueirinha, porém ressalta que não os vê como não indígenas simplesmente por poucos falarem a língua nativa:

Eu percebo assim também que a diferença da cultura deles (dos Kaingang) é a questão de mistura. Existe uma história pra isso, não foi perdido por acaso assim... Não é porque o índio não quer falar mais a língua, não! Existe uma história, aqui na Terra Indígena Mangueirinha, de que os fazendeiros moravam aqui e começaram a se misturar, né. E na época, quando foi feita a demarcação de terra, tinha alguns não indígenas que falavam que também tinham direitos e o governo na época não conseguiu dar o direito que eles tinham, os posseiros, né (os não índios). Tinha aqueles bem pobrezinhos, às vezes pior que o índio, o que o governo fez na época, não podia fazer um despejo e falar você tem que sair daqui, porque o coitado morava no mato também, e o índio também aceitou, né. Não porque ele queria, mas ele não percebeu que mais tarde poderia ser prejudicado, e foi o que aconteceu, né... Aqueles não indígenas que morava no paiolzinho no mato queria ficar. Daí o índio bonzinho disse 'tudo bem, quer ficar, fique'. Depois a piazadinha cresceram, e o índio casou com aquele filho do branco e onde foi misturando, e aconteceu que hoje já não falam mais a língua, então foi em função da história... Às vezes, as pessoas dizem 'ele não é mais índio, ele perdeu a língua', não é bem assim, a gente tenta explicar, que não foi bem assim, por exemplo, os alemão, os polonês, os italiano que vieram aqui pro Brasil, alguns ainda falam a língua, mas os jovens, a geração nova já não falam mais. Foi o que aconteceu com os Kaingang aqui de Mangueirinha. Aqui, as crianças aprendem falar o Guarani em casa, vendo os pais falar, daí na escola aprende a escrita. (Cacique Guarani).

Entre os Kaingang, a linhagem é patrilinear, ou seja, o filho é aquilo que o pai é, conforme explica Almeida (2013), por isso alguns povos permitem que o homem índio se case com uma não índia, porque seus filhos serão considerados igualmente índios. Agora, quando uma mulher indígena decide casar-se com um não índio, ela é expulsa da aldeia, pois seus filhos não serão considerados indígenas pela comunidade.

Sobre os casamentos mestiços, Canclini (2008) argumenta que, de fato, causaram parte da grande explosão híbrida de culturas que aconteceu no século XX, quando as culturas deixaram de ser "puras", nos termos do autor, e passaram a ser heterogêneas. 
A religiosidade dos Guarani é algo que chama bastante atenção nos depoimentos coletados. Eles têm uma casa de reza, na qual se reúnem todas as noites para o ritual. Entretanto, para alguns dos indígenas que trabalhavam nas empresas da região, o horário de trabalho não permitia que eles participassem dos rituais de rezas, o que contribuiu para que desistissem de trabalhar nas empresas, conforme relata o entrevistado G3: "Teve índio que não aguentou o repuxo, trabalhava no pesado, levantava cedo, chegava tarde, não dava tempo nem de ir para casa de reza. Desistiram, né" (Entrevistado G3).

O Xamã (Tchamain, na pronúncia), também, é muito importante para os Guarani da TI Mangueirinha. Esse quase sempre é uma mulher, a mais velha da aldeia, como também observou Bonamigo (2006), entre os Guarani Mbya em Paranaguá, PR. A Xamã tem a função de repassar conhecimentos ancestrais, dar conselhos sobre decisões importantes e manter a paz e harmonia dentro da aldeia.

O cacique Guarani ressalta que, para os Guarani, Xamã e Pajé são duas coisas diferentes. Algumas etnias indígenas atribuem igualdade para os dois, porém, para os Guarani da TI Mangueirinha, o/a Xamã é uma pessoa do bem e o/a Pajé é alguém que age para o mal:

Nós temos a Xamã, que é melhor chamar Xamã do que Pajé, porque Pajé é uma palavra emprestada, né, quer dizer uma pessoa feiticeira, que faz mal... Macumbeira. E a Xamã é uma pessoa assim velha, que tem experiência de vida, de doença, tem um conhecimento espiritual, natural, por isso que a gente fala Xamã, a pessoa mais velha da comunidade, quase sempre a mulher. (Cacique Guarani).

Entre os Kaingang, atualmente, as religiões são entre católica e evangélica, e as celebrações acontecem da mesma forma que na sociedade não indígena, com a ressalva de que, na católica, a missa é realizada por um ministro e, eventualmente, pelo padre.

Cabe ressaltar que muito da hibridez cultural vista dentro da TI Mangueirinha atualmente não foi espontânea, está carregada de muita imposição da política não indígena, que baseava suas diretrizes na preposição de que os indígenas tinham uma "incapacidade relativa" e que precisavam ficar sob a tutela do Estado até que estivessem aptos a serem integrados à nação (CORDEIRO, 1999).

Existem muitas diferenças entre os Guarani e os Kaingang da TI Mangueirinha, que são próprias de cada etnia e vem a enriquecer os estudos etnográficos da região. Entre os Kaingang há um grande engajamento nos movimentos indígenas, já entre o povo Guarani essa preocupação é bem mais recente. Isso ocorre pelo fato da posse da terra ser dos Kaingang e os Guarani serem mais reservados, fazendo com que estes tenham a tendência de autorizar os Kaingang a representá-los fora da TI Mangueirinha. Mesmo assim, o cacique Guarani busca incentivar os jovens de seu grupo a trabalhar externamente à aldeia, numa tentativa de a etnia alcançar mais autonomia e se empoderar em relação à sociedade envolvente.

\subsection{Assalariamento como consequência da modernidade}

A inserção dos indígenas no trabalho formal ainda é recente, contudo, entre os Kaingang, a comunidade já está habituada à rotina do trabalho assalariado. Entre uma conversa e outra com os moradores da Aldeia Sede, percebe-se a familiaridade que eles têm com os ônibus de transporte coletivo das empresas que circulam pela aldeia para pegar ou deixar os(as) trabalhadores(as) indígenas, em vários horários do dia. 
Eles entram aqui e vão subindo e pegando o pessoal. Passam pra diante do Paiol Queimado, a cada pouco tem um ponto. Daí, daqui eles voltam pra pegar os que faltam ali do outro lado, pegam mais uns lá no Trevo e vão embora. Enche um ônibus só de índio aqui, os brancos vão com outro. (Entrevistado K12).

Entre os Guarani, as informações não são espontâneas, é necessário criar confiança social antes de algum deles falar. E procuram não falar dos "parentes", como chamam seus pares. Usam a língua nativa para se comunicar entre si e deixam o entrevistador sempre à margem de suas conversas pessoais. Somente depois da recorrência de algumas visitas é que se obteve a confiança suficiente para um diálogo mais aberto.

Para o cacique Guarani, a barreira cultural dificulta a adaptação ao trabalho assalariado, por isso que a principal atividade na Aldeia Palmeirinha do Iguaçu ainda é o artesanato, que confeccionam em suas próprias casas, no horário que melhor Ihes convém, e vendem na beira do asfalto que passa dentro da aldeia. O cacique acredita que a mudança brusca de hábitos exigida pelo trabalho assalariado é a principal causa das desistências:

A maior parte desistiu por motivo de, talvez de uma cultura diferente, enfim, tinha que ficar na cidade, levantar mais cedo, cumprir ordens. Mas acho que foi legal, tem alguns ainda que estão trabalhando, maioria jovens. (Cacique Guarani).

As duas etnias, Guarani e Kaingang, responderam de formas distintas ao processo de inserção ao mercado de trabalho. Segundo os caciques de ambos os grupos, no início desta pesquisa, em dezembro de 2013, havia aproximadamente 20 indígenas Guarani e 90 Kaingang trabalhando nas empresas da região sudoeste do Paraná. Entretanto, em novembro de 2014, eram 15 indígenas Guarani e 120 Kaingang formalmente contratados e, em outubro de 2015, eram 4 indígenas Guarani e 200 Kaingang trabalhando nas empresas manufatureiras da região sul do Brasil. Houve uma queda de $80 \%$ no número de indígenas Guarani e um crescimento de $222 \%$ no número de Kaingang assalariados durante o período em que esta pesquisa de campo se realizou, no ano de 2015, em relação ao período da pesquisa exploratória, feita em 2013.

Esse receio de alguns indígenas diante do mercado de trabalho formal pode ser explicado pelas diferenças culturais na definição do que é a categoria sociológica trabalho. Woleck (2002) ressalta que, entre povos tradicionais, o trabalho não era pensado como fonte de riqueza e as características de mercado que hoje estão atreladas a ele não existiam. Tratava-se exclusivamente do esforço realizado para sobreviver, que era importante pelo seu valor de uso, não pelo valor de troca. No caso dos indígenas da TI Mangueirinha, tal atribuição ao trabalho é perceptível principalmente entre os Guarani.

Das duas mulheres Guarani que continuam trabalhando, nenhuma realizava trabalhos tradicionais dentro da $\mathrm{TI}$ antes de trabalhar externamente às aldeias. A ocupação anterior era o trabalho doméstico, o que as tornava dependentes monetariamente da família. Assim, o fato de ter uma fonte de renda própria trouxe mais liberdade e autonomia para ambas, inclusive para tomar a iniciativa de morarem sozinhas com os filhos, como argumentam as entrevistadas G1 e G2:

Ah! Na verdade, eu não tinha nada o que fazer. Daío meu pai e a minha mãe são aposentados e eu tinha que tá pedindo as coisa, sabe. Agora o que eu ganho é pra mim e pro meu filho, daí mudou! Eu compro as coisas que quero, sem ter que ficar pedindo. O que o pai e a mãe ganha é pra eles, o que eu ganho é pra mim. Ah, que nem agora, eu já comprei minha casa, vou começar a fazer na metade do mês que vem. Eu também compro comida, e roupa, essas coisas. Sô, como que eu posso dizer? Independente mesmo. (Entrevistada assalariada G2).

INTERAÇÕES, Campo Grande, MS, v. 21, n. 3, p. 461-477, jul./set. 2020 
Eu fiquei sabendo desse serviço porque vieram pra avisar, pra quem quisesse trabalha... Daí eu resolvi, daí eu dei o nome pro cacique, pra sustentar meus filho, que o pai deles não ajuda, nós vivia do Bolsa Família, dependia do povo. Agora melhorou, né, tenho pra comida, roupa, calçado. Eu vou tentar continuar trabalhando. Todo mundo tem aqui [pedaço de terra], mas eu não tenho. Pra gente que é sozinha com filho pequeno, lida na terra é mais difícil, né, daí tem que trabalha. (Entrevistada assalariada G1).

Os conhecidos dos indígenas Guarani que desistiram de seus empregos formais relatam que eles trabalhavam com agricultura e artesanato e optaram por voltar às atividades tradicionais. Alguns dentro e fora da $\mathrm{Tl}$, como é o caso de dois jovens que trabalharam por três meses em uma empresa de frango e atualmente trabalham com hortaliças numa fazenda no Rio Grande do Sul. Embora a distância e os ciclos de plantio e colheita os forcem a passar três meses fora de casa, o trabalho agrícola é melhor que o anterior, como argumentam:

Lá a gente trabalha num serviço de trabalhador rural, né. Tô trabalhando já faz 22 meses, tinha uns amigos meu que trabalhava antes lá e convidou nós pra ir pra lá, eles era daqui. Dai é tudo fichado, trabalha das 7:00 até as 18:00, só que com hora extra. E dai é tudo livre, casa, comida e até as coisas de higiene, essas coisas. Antes eu trabalhava ali em Pato Branco, no corte de frango, trabalhei 90 dias, mas não gostava. Vixe, era puxado, e o salário era bem mais menor. E lá assim, é tudo fichado, mas eles não pagam só o que tem na carteira, eles pagam mais pelas caixas, pela quantidade da produção, né. Daí eu fico lá uns 90 dias e um mês e pouco aqui, sempre assim, e a gente recebe igual. Lá eu gosto, queria continuar, só que é longe, né, daqui, da umas 12, 13 horas de viagem de ônibus. Assim, mudou muito pra melhor, tipo financeiramente, mas da comunidade eu tô mais afastado agora, porque não dá tempo, né. Se for pra pensar bem, é um pouco ruim, porque a gente fica mais fora do que dentro da aldeia. Mas, se eu sair de lá, também aqui eu vou trabalhar fora de novo, porque aqui dentro da aldeia a gente trabalha na crítica assim, eu não gosto muito. (Entrevistado G3).

Entre os Kaingang, o perfil dos trabalhadores é de jovens que têm um núcleo familiar mantido por outras fontes de renda, especialmente a agricultura, e que tem no trabalho assalariado uma forma de diversificar os meios de vida, visto que dentro da Tl as opções de trabalho são na agricultura e no artesanato, que não são tão interessantes para a nova geração de jovens (da mesma forma que para as duas indígenas Guarani), o que resulta no baixo índice de desistências do trabalho assalariado e aumento gradual dos indígenas que estão se inserindo nesse mercado, como argumenta o cacique Kaingang:

Até então os mais velhos trabalhavam com o artesanato, agricultura também era pouco, e a piazada ficava aí na beira do asfalto. A primeira empresa que veio aqui foi a Atlas, no próximo ano já veio a empresa de frangos [Aurora]. E agora nós temos mais de 200 pessoas trabalhando fora, homens e mulheres, quase só jovens, porque esses índios não gostam da lavoura, tem índio que não gosta. (Cacique Kaingang).

O cacique Kaingang argumenta que outras transformações econômicas aconteceram dentro da TI Mangueirinha, mais ou menos na mesma época em que os indígenas passaram a se assalariar nas empresas da região, principalmente na produção agrícola.

O fato de as terras indígenas serem de posse coletiva dificultava a aquisição individual de recursos para a produção, e os puxirões (trabalhos agrícolas manuais coletivos) já não estavam surtindo bons resultados. Então, os indígenas mais experientes na agricultura se uniram às lideranças para fundar a Associação de Produtores Rurais Indígenas de Mangueirinha (APROIMA), pela qual conseguem investir na agricultura o dinheiro público que é designado às terras indígenas 
e obter recursos próprios para realizar os antigos "puxirões" de forma mecanizada, otimizando a produção, como argumenta o cacique:

Logo que eles começaram a trabalhar fora, a gente também começou com a nossa associação de produtores indígenas. E a gente tem uma lavoura coletiva que é de 40 alqueires, na época ela dava 20-25 alqueires, e essa lavoura a gente usava ela pra compra de máquinas e manutenção das máquinas nossas. Daí os nossos tratores a gente ganhou do programa do governo, emenda parlamentar, né. E a gente foi trabalhando a lavoura dos índios, com essa lavoura que a gente conseguia fazer só a manutenção das máquinas, hoje, aí com aquele dinheiro dessa lavoura de 40 alqueires a gente faz a manutenção das máquinas e compra mais equipamento. E a gente pode dar horas-máquina pros índio sem custo nenhum, a gente não cobra nem o diesel deles. [...] dessa nossa associação a gente já conseguiu só aqui pra Sede três tratores traçados, ganhamos dois do deputado, e a gente comprou um novo com o lucro dessa associação da nossa lavoura coletiva. A gente comprou um caminhão, a gente comprou plantadeira, a gente comprou dois pulverizadores automáticos, então, a gente está bem estruturado aqui [...]. (Cacique Kaingang).

A busca por autonomia e empoderamento dos Guarani levou à diversificação das suas fontes de renda e a melhorar o seu meio de vida, conforme diz o cacique:

Os mais velhos trabalham a agricultura. A gente tinha uma parceria pra desenvolver a agricultura, onde nós tinha que ter essa parceria por que todo recurso que é destinado pra comunidade indígena tem que ter uma associação, então por isso que nós até esses dias tinha essa parceria (com os Kaingang). Agora nós estamos montando uma outra associação dentro aqui que é dos Guarani mesmo, pra gente poder trabalha melhor, porque todo recurso que vem vai pra associação, e sempre quem administrava era eles, né [os Kaingang]. (Cacique Guarani).

Embora as lideranças venham buscando diversificar cada vez mais as atividades produtivas dentro da TI, elas não são suficientes para envolver todos os indígenas e demandam cada vez menos mão de obra, especialmente as atividades agrícolas mais mecanizadas. Nesse caso, as famílias Kaingang estão cada vez mais pluriativas, buscando a diversificação da renda por meio do trabalho assalariado dos membros jovens da família. A estratégia de venda da força de trabalho, quando as condições do meio rural não são favoráveis a todos os integrantes da comunidade, é própria das populações tradicionais. Trata-se de uma tentativa de buscar entesouramento mercantil para manter o seu modo de vida, adicionando uma nova variável à vida tradicional, o salário (CHAYANOV, 1981; FRIEDMANN, 1978).

A facilidade no transporte e na alimentação durante o expediente de trabalho é aliada na opção pelas empresas manufatureiras, pois, ainda que o tempo fora da comunidade seja longo, eles conseguem adaptar-se e continuar morando na TI, como argumenta o entrevistado assalariado K1:

A empresa dá o transporte, daí pega aqui, espera no ponto, né, tudo de graça daí. A comida daí a gente come lá mesmo, eles trazem a janta, depois descontam no salário, mas é baratinho. Dai é bom, né, dai eu penso em trabalhar fora sempre, porque ajuda bastante, né, é bom trabalhar. Mas eu penso sempre em morar aqui e trabalhar fora. (Entrevistado assalariado K1).

Ambos os povos buscam maneiras de resistir em meio à sociedade envolvente, cada um à sua maneira, descobrindo formas de manter e reinventar sua própria cultura.

O Quadro 1 sintetiza as causas da (não) adaptação dos índios ao assalariamento: 
Quadro 1 - Síntese dos condicionantes do assalariamento indígena na TI Mangueirinha

\begin{tabular}{|c|c|c|}
\hline \multirow{2}{*}{ Fator } & \multicolumn{2}{|c|}{ Etnia } \\
\hline & Guarani & Kaingang \\
\hline Agricultura & $\begin{array}{l}\text { Realizada de forma individual ou na } \\
\text { forma tradicional de puxirões, o que } \\
\text { demanda muita mão de obra. }\end{array}$ & $\begin{array}{l}\text { Mecanizada, realizada por meio de } \\
\text { associações, e demandando pouca } \\
\text { mão de obra. }\end{array}$ \\
\hline Artesanato & $\begin{array}{l}\text { Utilizado como uma das principais } \\
\text { fontes de renda para a maior parte } \\
\text { das famílias. }\end{array}$ & $\begin{array}{l}\text { Confeccionado principalmente } \\
\text { nas escolas como incentivo de } \\
\text { preservação cultural, não é utilizado } \\
\text { como fonte de renda. }\end{array}$ \\
\hline Relações Interétnicas & $\begin{array}{l}\text { Resistentes, sobretudo com o não } \\
\text { indígena. }\end{array}$ & $\begin{array}{l}\text { Em geral, relacionam-se bem com os } \\
\text { não índios. }\end{array}$ \\
\hline \multirow{2}{*}{ Língua } & $\begin{array}{l}\text { Língua materna predominante, } \\
\text { fluente entre todos os indígenas. }\end{array}$ & Língua portuguesa é predominante. \\
\hline & $\begin{array}{l}\text { A língua portuguesa é pouco } \\
\text { utilizada na comunidade. }\end{array}$ & $\begin{array}{l}\text { A língua materna é pouco falada por } \\
\text { todos os indígenas. }\end{array}$ \\
\hline
\end{tabular}

Fonte: dados coletados e organizados pela pesquisadora Aline Cavalheiro.

Percebe-se que esses grupos sociais respondem de formas diferentes a diversos fatores socioculturais. De modo geral, ambos optaram por manter a cultura de maneira distinta, enquanto os Kaingang têm hábitos mais flexíveis à interação com a sociedade envolvente, os Guarani mantêm-se mais reservados. Ambos os modos de vida refletem pontos positivos e negativos para seus povos: os Kaingang vêm conseguindo um empoderamento econômico e político maior do que os Guarani; por outro lado, os Guarani têm preservado aspectos culturais valiosos, como a língua materna e o artesanato.

Essas características explicam também as diferenças nas estratégias dos Kaingang e Guarani em relação ao assalariamento, uma vez que o assalariamento formal é uma categoria capitalista de trabalho, regida por leis e normas estritamente não indígenas, com as quais os Kaingang têm mais proximidade que os Guarani.

\section{CONSIDERAÇÕES FINAIS}

A configuração da TI Mangueirinha não permite a subsistência de todas as famílias indígenas pela maneira tradicional, tornando-os cada vez mais dependentes do uso do dinheiro para suprir as suas necessidades. A história conta que o uso da venda da força de trabalho é uma estratégia utilizada há bastante tempo pelos indígenas para diversificar as fontes de renda, no entanto o assalariamento formal é um fenômeno mais recente e radical.

Na última década, houve uma reconfiguração importante no exercício das atividades internas e externas à comunidade, essencialmente entre os Kaingang. Essas mudanças permitiram otimizar a agricultura, no entanto também transformaram as relações interpessoais. O trabalho agrícola, que anteriormente era manual e exigia uma intensa reciprocidade entre as famílias, agora é regulado pelas associações indígenas que se utilizam de máquinas agrícolas nas áreas coletivas.

Em relação ao processo de inserção no mercado de trabalho das empresas regionais, foram identificados três perfis de trabalhadores indígenas assalariados: 1) os que se adaptaram à dinâmica do trabalho assalariado (especialmente os Kaingang); 2) os que não estão se adaptando 
e se frustram com o mercado de trabalho (especialmente os Guarani); e 3) os que viram no assalariamento a oportunidade de adquirir bens no curto prazo e que retornam ao mercado de trabalho a cada nova necessidade de mercadoria (em ambas as etnias).

Desse modo, pode-se dizer que as estratégias de assalariamento dos dois povos da TI Mangueirinha nas empresas manufatureiras da região resultam de um quadro socioeconômico e cultural distinto, e que esses povos encontram na interação com a sociedade moderna diversas maneiras de manter seu meio de vida. As motivações são invariavelmente causadas pela necessidade cada vez maior do uso do dinheiro no cotidiano, entretanto existem acessos a recursos culturais e humanos diferenciados entre os Guarani e Kaingang da TI Mangueirinha que condicionam a uma trajetória diferenciada de inserção no mercado de trabalho regional.

É importante ressaltar que o assalariamento indígena nas empresas manufatureiras da região é uma novidade, e é grande o potencial de ocorrer amplas transformações econômicas e sociais, principalmente entre os Kaingang. Pode-se dizer, ainda, que o futuro dessa TI guarda muitas surpresas, pois as sementes de mudanças estão sendo plantadas hoje e não sabemos quão híbrida estará a TI Mangueirinha no futuro.

\section{REFERÊNCIAS}

ALMEIDA, Antonio C. Da aldeia para o Estado: os caminhos do empoderamento e o papel das lideranças Kaingang na conjuntura do movimento indígena. 2013. Tese (Doutorado em Ciências Sociais)- Pontifícia Universidade Católica de São Paulo, São Paulo, 2013.

BONAMIGO, Zélia Maria. A economia dos mbya-guaranis: troca entre homens e entre deuses e homens na ilha da Cotinga em Paranaguá-PR. 2006. Dissertação (Mestrado em Antropologia)- Universidade Federal do Paraná (UFPR), Curitiba, PR, 2006.

BOURDIEU, Pierre. Coisas ditas. São Paulo: Brasiliense, 2004.

CANCLINI, Nestor. As culturas híbridas em tempos de globalização. In: CANCLINI, Nestor. Culturas híbridas. 4 ed. São Paulo: Edusp, 2008. p. xvii-xl.

CHAYANOV, Alexander V. Sobre a teoria dos sistemas econômicos não capitalistas. In: SILVA, José Graziano; STOLCKE, Verena (Org.). A questão agrária. Weber, Engels, Lênin, Kautsky, Chayanov, Stálin. São Paulo: Ed. brasiliense, 1981.

CLASTRES, Pierre. A sociedade contra o estado: pesquisa de antropologia política. São Paulo: Cosac Naify, 2003.

CORDEIRO, Enio. Política Indigenista Brasileira e a Promoção Internacional dos Direitos das Populações Indígenas. Brasília: Instituto Rio Branco; Fundação Alexandre Gusmão; Centro de Estudos Estratégicos, 1999.

ELLIS, Frank. Rural livelihoods and diversity in developing countries. Oxford: Oxford University, 2000.

FRIEDMANN, Harriet. World Market, State and Family Farm: social bases of household production in the era of wage labour. Comparative Studies in Society and History, Cambridge, v. 20, n. 4, p. 545-86, 1978.

GRAZIANO DA SILVA, José. O novo rural brasileiro. Revista Nova Economia, Belo Horizonte, v. 7, n. 1, p. 43-81, maio de 1997. 
INSTITUTO SOCIOAMBIENTAL - ISA. Kaingang. Povos Indígenas no Brasil. Disponível em: http://pib. socioambiental.org/pt/povo/kaingang. Acesso em: 29 jun. 2015.

LAZZAROTTO, Elizabeth Maria et al. Condições de saúde das comunidades indígenas Guarani e Kaigang. In: SEMINÁRIO NACIONAL- ESTADO E POLÍTICAS SOCIAIS NO BRASIL, 3., 2007, Cascavel. Anais [...]. Cascavel: UNIOESTE, 2007.

LONG, Norman et al. The commoditization debate: labor process, strategy and social network. Wagening: Agricultural University of Wagening, 1986.

MINAYO, Maria Cecília de Souza (Org.). Pesquisa social: teoria, método e criatividade. 17. ed. Petrópolis, RJ: Vozes, 1994.

MOURA, Patrícia G.; BATISTA, Luciana R. V.; MOREIRA, Emília A. M., População indígena: uma reflexão sobre a influência da civilização urbana no estado nutricional e na saúde bucal. Revista de Nutrição. Campinas, v. 23, n. 3, p. 459-65, maio/jun. 2010.

MOTA, Lúcio Tadeu. As guerras dos índios Kaingang: a história épica dos índios Kaingang no Paraná, 17691924. Maringá, PR: Editora da Universidade Estadual de Maringá, 1994.

NOELLI, Francisco Silva. Repensando os rótulos e a história dos Jê no Sul do Brasil a partir de uma interpretação interdisciplinar. In: MOTA, Lúcio Tadeu; NOELLI, Francisco Silva; TOMMASINO, Kimiye (Org.). Uri e Wãxi: estudos interdisciplinares dos Kaingang. Londrina: Editora UEL, 2000. p. 9-57.

PERONDI, Miguel Ângelo. Diversificação dos meios de vida e mercantilização da agricultura familiar. Orientador: Sergio Schneider. 2007. Tese (Doutorado em Desenvolvimento Rural) - Universidade Federal do Rio Grande do Sul (UFRGS), Porto Alegre, RS, 2007.

PIRES, Maria L. M. Guarani e Kaingang no Paraná: um estudo de relações intertribais. 1975. Dissertação (Mestrado em Antropologia Social) - Universidade de Brasília, Brasília-DF, 1975.

POLANYI, Karl. A grande transformação. 2. ed., Rio de Janeiro: Campus, 2000.

ROSA, Marcelo Caetano de Cernev. Notas sobre a presença Guarani no estado do Paraná. Elementos de cosmologia e história. Mediações - Revista de Ciências Sociais. Londrina, v. 4, n. 1, p. 33-46, jan./jun. 1999.

SCHNEIDER, Sergio. A pluriatividade na agricultura familiar. Porto Alegre: UFRGS, 2003.

SOUZA, Paulo Renato Costa. A determinação dos salários e do emprego nas economias atrasadas. 1980. Tese (Doutorado em Filosofia e Ciências Humanas)- Universidade Estadual de Campinas, Campinas, 1980.

TOMMASINO, Kimiye. Território e territorialidade Kaingang. Resistência cultural e historicidade de um grupo Jê. In: MOTA, Lúcio Tadeu; NOELLI, Francisco Silva; TOMMASINO, Kimiye (Org.). Uri e Wãxi: estudos interdisciplinares dos Kaingang. Londrina: Editora UEL, 2000. p. 191-226.

WOLECK, Aimoré. O trabalho, a ocupação e o emprego: uma perspectiva histórica. Revista de Divulgação Técnico-científica do Instituto Catarinense de Pós-Graduação, Blumenau, v. 1, p. 1-15, jan./jun. 2002. 


\section{Sobre os autores:}

Antonio Cavalcante Almeida: Pós-Doutor em Desenvolvimento Regional pela Universidade Tecnológica Federal do Paraná (UTFPR). Doutor em Ciências Sociais pela Pontifícia Universidade Católica de São Paulo (PUC-SP). Mestre em Sociologia Política pela Universidade Federal de Santa Catarina (UFSC). Graduado em Ciências Sociais pela Universidade Federal do Ceará (UFC). Professor de Sociologia no Instituto Federal de Educação, Ciência e Tecnologia do Ceará (IFCE). E-mail: antoniocavalcant@hotmail.com, ORCID: http://orcid.org/0000-0001-8479-3236

Aline Cavalheiro: Mestre em Desenvolvimento Regional pela Universidade Tecnológica Federal do Paraná (UTFPR). Graduada em Enfermagem pela Faculdade de Pato Branco (FADEP). Servidora Pública da Secretaria Municipal de Saúde da Prefeitura Municipal de Coronel Vivida, Paraná. E-mail: a_linecavalheiro@hotmail.com, ORCID: http://orcid.org/0000-0002-4138-9476

Miguel Ângelo Perondi: Pós-doutorando no Departamento de Economia da Universidade da Califórnia, Riverside. Doutor em Desenvolvimento Rural pela Universidade Federal do Rio Grande do Sul (UFRGS). Mestre em Administração pela Universidade Federal de Lavras (UFLA). Engenheiro agrônomo pela Universidade Federal do Paraná (UFPR). Professor na Universidade Tecnológica Federal do Paraná (UTFPR). E-mail: miguelangeloperondi@gmail.com, ORCID: http://orcid.org/0000-0003-4382-4571 
